\title{
Productivity of Trainers Seen From Achievement Motivation, Creativity and Working Climate
}

\author{
Kohar \\ Post Graduate Program, State University of Padang, Indonesia
}

\begin{abstract}
This study aimed to determine: (1) The direct effect of achievement motivation of trainer on creativity of trainer, (2) direct effect partially or simultaneous achievement motivation and creativity of trainer on working climate, (3) direct effect partially or simultaneous achievement motivation of trainer, creativity of trainer and working climate of trainer on productivity of trainer and (4) indirect effect on the productivity of motivation and creativity trainers through the work climate. The study was conducted using quantitative methods with descriptive research and associative. The population of this study are all trainers at Center of Development and Empowerment for Teacher and Education Personnel (PPPPTK) Medan, PPPPTK Bandung and PPPPTK Malang with number 276 people. To determine the sample used Slovin formula thus obtained a sample of 75 people. The instrument used to collect the data was a questionnaire with Likert scale. The data analysis technique used is descriptive techniques and path analysis techniques. The results of this study indicate that: (1) Achievement motivation of trainer direct influence on the creativity of trainer by $55.2 \%$, (2) Achievement motivation of trainer and creativity of trainer partially directly influence on the working climate of $20.5 \%$ and $16 \%$. While the simultaneous achievement motivation of trainer and creativity of trainer provide a direct influence on the working climate at $63.3 \%$, (3) Achievement motivation of trainer, creativity and working climate directly affect the productivity of trainer partially $6.1 \%, 11.6 \%$ and $12 \%$. While the simultaneous achievement motivation of trainer, creativity and working climate gives a direct influence on the productivity of trainer at $72.6 \%$; (4) In addition to the direct effect, achievement motivation and creativity also indirectly affect the productivity of trainers through the working climate, respectively amounted to $2.5 \%$ and $1.9 \%$.
\end{abstract}

\subsection{Background}

\section{Introduction}

PPPPTK as a training institution, is highly dependent on the existence and productivity of trainers in managing and implementing education, teaching and training. The role of trainers to be very important, both in relation to the achievement of organizational goals and in order to improve the quality of education in Indonesia. For the competence and creativity of the trainers as facilitators should be well maintained. So that trainers can be a professional work, trainers not only serve as a tool for cultural transmission, but is also able to transform culture toward a culture that is dynamic and requires mastery of science and technology, high productivity and the quality of work that is able to improve competitiveness. Trainers is not merely to be able to manage and implement training but also must be able to be a designer and developer of training programs for his/her field.

In connection with a productivity of trainers contained in the Regulation of the Institute of Public Administration No. 3 of 2010 on Technical Guidelines for Functional Trainers and credit figures containing about 7 trainers productivity assessment indicators, namely: professional development and skills, education and teaching, research and development, dedication in the community, participation in scientific activities, improving the quality of education and scientific awarded. ${ }^{1]}$ Trainers demanded to have the maximum performance that productivity of PPPPTK will remain intact. Duties and function of trainers contained in Permenpan No. 14 of 2009 trainers are required to collect credit points according to ranks and positions, as an indicator of the performance of trainers determination of the order of rank can be increased by the applicable laws and regulations. Obtaining credit is determined based activities of training that trainers have done within a certain time. ${ }^{2]}$

Based on data from the Ministry of Education and Culture, the number of trainers at PPPPTK Field Technology trainers there are 276 people. Of these there are 51 people or $18.48 \%$ trainers who have problems against promotion caused by problems with the credit number gathering details as shown in Table 1 below. 
Tabel 1. Number of Trainer at PPPPTK Technology

\begin{tabular}{|c|l|c|c|c|}
\hline No. & Institution & $\begin{array}{c}\text { Number of } \\
\text { Trainer }\end{array}$ & $\begin{array}{c}\text { Number of Trainer } \\
\text { having problem with } \\
\text { credit number }\end{array}$ & $\begin{array}{c}\text { Persentage of } \\
\text { Trainer Problematic } \\
(\boldsymbol{\%})\end{array}$ \\
\hline 1 & PPPPTK Medan & 64 & 18 & 28,13 \\
\hline 2 & PPPPTK Bandung & 90 & 24 & 37,50 \\
\hline 3 & PPPPTK Malang & 122 & 9 & 7,38 \\
\hline & Keseluruhan & $\mathbf{2 7 6}$ & $\mathbf{5 1}$ & $\mathbf{1 8 , 4 8}$ \\
\hline
\end{tabular}

Data Source: Pusbangtendik 2012

Based on these data, it can be stated that a large number of trainers in PPPPTK Technology have problems on their productivity. These conditions will directly affect the productivity of PPPPTK Technology in carrying as its function, an extension of central government institutions in the district area. The low productivity of trainers will directly result in low productivity of PPPPTK Technology in running programs related to the duties and function of this institution.

Achievement of an organization's duties also related to work climate. The components that make up the atmosphere of this practice include a more participative decision making and patterned group, the presence of current levels of communication that flows throughout the organization adequately in terms of quantity and quality, the creation of conditions in such a way so as to encourage and stimulate employees to work hard, the presence of hope fully to the human resources as the capital of the organization, the recognition of the influence of subordinates in carrying out job duties, and the provision of adequate technology by the organization in accordance with the need to perform job duties .

Achievement motivation within trainers when associated with a job, would drive the spirit and creativity to continuously improve potency and performance. Achievement motivation owned trainers will create the ability to solve a wide range of work and obstacles encountered more leverage. So it can be stated that to achieve maximum performance takes a pretty strong motivation of all components of the organization, in order to create a positive energy in the achievement of organizational goals.

Based on the above, it is necessary to do in-depth research empirically 3 variables: achievement motivation of trainer, creativity of trainer and working climate of trainer and the productivity of trainer at PPPPTK Technology.

\subsection{Productivity of Trainer}

\section{Literature Review}

Productivity comes from English product: result, outcome develop into productive word which means producing, and productivity: having the ability to the make or create; creative. The words used in Indonesian into productivity, which means strength or ability to produce something. Rollos in Ali Yassin et al (2013) provide a definition of productivity "the productivity as that the which people can produce with the least effort". ${ }^{3]}$ Furthermore, Robbins and DeCemzo (2003:402) describes the productivity is the entire output of goods and services produced divided by the inputs needed to generate from the output. ${ }^{[4]}$ Productivity is the union of the people with the operating variables. Therefore, effective organization will maximize productivity by successfully integrating people into the entire operating system.

Anoraga (2005: 56-60) suggests that there are 10 factors that are desired by the employees to improve employee productivity, namely: (1) interesting work, (2) good wages, (3) the safety and protection in work, (4) work ethic and (5) the environment or good working facilities, (6) the promotion and development of themselves in line with the development of the company, (7) was involved in the organization's activities, (8) the understanding and sympathy for the problems personally, (9) the loyalty leader to employee, (10) Discipline of hard work. ${ }^{[5]}$

\subsection{Working Climate of Trainer}

McBrien and Brandt (1997:89) states "organizational climate, the sum of the values, culture, safety practices, and organizational structures within an organization that cause it to function and react in particular ways". ${ }^{[6]}$ Each organization will have a different working environment. Diversity work designed in the organization, or individual properties are set to describe the difference. Furthermore, Litwin and Stringer (1968) states "perceived effects of the formal system, the information style of managers and other important environment factors on the attitudes and motivation of belief values of the people who work in a particular organization." ${ }^{[7]}$ This understanding gives an explanation that working environment is everything that is contained in the work environment is internalized as subjective influence of the formal system, the style information from managers, and other important environmental factors on attitudes, beliefs, values and motivations of the people who work in a particular organization. 
So the climate is a set of equipment from a working environment that is perceived directly or indirectly by the employees working in this environment and assumed to be the major forces that affect their behavior in the work. Working climate is a picture of the quality, ambience and character that appears in norms and values, interpersonal relationships, teaching and learning environment, organizational structure, a positive bond with the institution and the physical environment where the trainer work.

\subsection{Achievement Motivation of Trainers}

In 1969, Clayton Alderfer revised theory of Maslow's hierarchy of Needs, by introducing Theory ERG (ERG Theory). Contributions Alderfer on organizational behavior conferred on the ERG theory ( Existence, Relatedness, and Growth ) and was created to align the motivation theory of Maslow is closer to empirical research (Alderfer 's contribution to organizational behavior was dubbed the ERG theory) (Existence, Relatedness, and Growth), and was created to align Maslow's motivation theory more closely with empirical research,". Models ERG theory is described as follows. ${ }^{[8]}$

Figure 1 . Clayton Alderfer 's ERG Theory

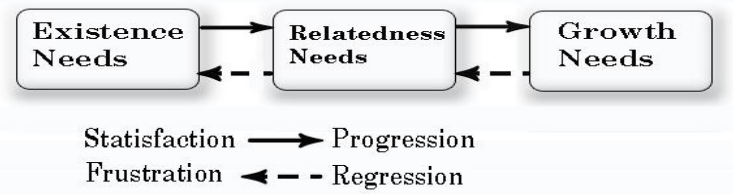

Source: Clayton Alderfer, ERG Theory of Motivation, p . 1, 2007 ( http://www.Envision Software ERG Theory of Motivation clayton p.alderfer.mht )

The need for achievement is motivation in every activity, so it is a motivation for the work and creativity in his work. Mc Clelland (1953) provide a sense of achievement motivation as follows: " achievement motivation is desire to do well not so much for the sake of social recognition or prestige but to attain an inner feeling of personal accomplishment or ... Success in competition with some standard of excellence." ${ }^{[9]}$ From this it appears that the sense of achievement motivation is a person's desire to do things well and achieve success with the best standards.

\subsection{Creativity of Trainer}

J. Gallagher, (1985) defines "Creativity is a mental process by the which an individual creates new ideas or products, or recombines existing ideas and products, in a fashion that is novel to him or her" (creativity is something mental process by individuals a new idea or product, or a combination of the two, which in turn attached to him). ${ }^{[10]}$ Creativity is a high-level thinking skills which implies an escalation in the ability to think, in the mark by succession, discontinuity, differentiation, and integration between each stage of development. Creativity is a process or the ability of trainers reflecting smoothness, suppleness, and originality in thinking, and the ability to elaborate (develop, enrich, itemize), an idea in carrying out their duties and responsibilities, creativity trainers consists of two dimensions, namely the dimensions of thinking and behaving, dimensions of creative thinking can be measured by indicators of fluency, flexibility, originality, elaboration, and evaluation. Be creative dimensions measured by indicators of the sensitivity of observation, are imaginative, feel challenged by pluralism, willing to take risks and appreciate nature .

\section{Research Methods}

According explanation level, type of research is associative, which is a study that is connecting two or more variables (Sugiyono, 2007). ${ }^{[1]}$ This study is explanatory causal relationships in the form of a survey which aims to determine the pattern of causal relationships between exogenous and endogenous variable. This research site are PPPPTK Medan, PPPPTK Bandung and PPPPTK Malang. The time study conducted in April to August 2013. The population in this study were all trainers in PPPPTK Technology namely PPPPTK Medan, PPPPTK Bandung and PPPPTK Malang. Affordable population is 276 people. Because this study aims to get a general picture of how the productivity, motivation, creativity and working climate distinguish between trainers in three PPPPTK Technology, the sampling technique to be used is proportional random sampling technique in order to obtain a sample size of 75 people. The research data were collected from respondents processed and analyzed with descriptive and inferential statistical techniques. Descriptive statistical techniques used to determine the mean, standard deviation, mode, and median. While inferential statistics were used to test the hypotheses that have been formulated, namely the parametric statistics, such as by using path analysis. 


\section{Results and Discussion}

The results of this study describe that based on the average value, productivity of trainers can be said enough because the average value is $71.82 \%$ of the theoretical highest score (275), working climate of trainers can be considered as the average value is $73.88 \%$ of the theoretical highest score (220), achievement motivation of trainers is enough for the average value is $70.28 \%$ of the theoretical highest score (215), and trainers can be quite creative because the average value is $77,90 \%$ of theoretical highest score (225).

Based on the results of data processing of the obtained coefficients on Substructure - 1 pathway that is $\rho 21=0.743$. Furthermore, the coefficient of determination $R 2=0.552$. Proving the value of $F>F$ $(0,05: 1: 73)(90,000>3.972)$ gives the meaning that the path coefficient is significant or in other words that achievement motivation (X1) can explain creativity (X2).Furthermore, the coefficient on Substructure - 2 pathway that is $\rho 31=0.453$ and $\rho 32=0,400$. Furthermore, the coefficient of determination $\mathrm{R} 2=0.633$. Based on the evidentiary value of $F>F(0,05: 2: 72)(62.197>3.124)$ then it means that the coefficient is significant pathways simultaneously or in other words that achievement motivation (X1) and creativity (X2) together can explain working climate (X3). Similarly, the individual test with the $t$ test shows that the value of $t$ all path coefficients are 4.245 and 3.748. T count all path coefficients Substructure - 2 is greater than the table $=1.99$ which means that individual achievement motivation (X1) and creativity (X2) affecting the working climate (X3).

Based on the results of data processing in the path coefficients obtained Substructure -3 is $\rho Y 1=$ $0.247 ; \rho Y 2=0.341$ and $=0.347 \rho Y 3$. Furthermore, the coefficient of determination $\mathrm{R} 2=0.726$. Through the evidentiary value of $\mathrm{F}>\mathrm{F}(0,05: 3: 71)(62.703>2.374)$ can be interpreted that the coefficient is significant pathways simultaneously or in other words that achievement motivation (X1), creativity (X2) and working climate (X3) together can explain the productivity of trainer (Y). Similarly, the individual test with the $t$ test shows that the value of $t$ all path coefficients Substructure - 3 , respectively $2.382,3.362$, and 3.381. $\mathrm{T}$ count all path coefficients Substructure -3 is greater than the table $=1.99$ which means that individual achievement motivation (X1), creativity (X2), and working climate (X3) affect the productivity of trainers $(\mathrm{Y})$.

The higher achievement motivation, the better a person's creativity. The emergence of achievement motivation in self trainers will foster a spirit of healthy competition, will foster the individuals who are responsible and with high achievement motivation will form a creative personal trainers. Mc Clelland ( 1953 ) explains that achievement motivation is a person's desire to do things well and achieve success with the best standards.

Achievement motivation factor to be one of the deciding factors in an effort to increase the productivity of trainers. Achievement motivation as a form of encouragement that were born in the trainers themselves in activities or jobs is not always arise from his personal self, but sometimes motivation arises from outside the trainers themselves. With the drive to achieve this will provide a very significant influence on the task being performed and in turn will affect productivity.

To increase the productivity of trainers is largely determined by the level of creativity of the trainers themselves. This is logical because creativity is closely linked with the initiative and ability to cope with the problem. Rani and Dalal stated that "Creativity is the ability to produce work that is both novel ie original, unexpected and appropriate. To create means to the make or bring into existence something new". ${ }^{[12]}$ Creativity is a high-level thinking skills which implies an escalation in the ability to think, in the mark by succession, discontinuity, differentiation, and integration between each stage of development.

Furthermore, to optimize the productivity of trainers job creation climate becomes an important part that must be considered. In the performance of their duties trainers, of course, highly dependent on the working atmosphere and emotional bond between fellow trainers in order to build a sense of mutual respect in order to create a positive ethos or atmosphere. Unfavorable work climate will create less pleasant working atmosphere, which results in the spirit and performance of the trainers.

The results of this study indicate that achievement motivation, creativity and working climate simultaneously give a substantial contribution to improve productivity of trainers. These results can be understood as the productivity of trainers is essentially influenced by internal and external factors. Achievement motivation and creativity are factors that arise internally from within the trainers, while social working climate is a factor of the relationships between individuals. Working climate can be considered as an external factor.

\section{Conclusion}

Based on the research results, it can be some conclusions as follows: (1) There is a direct effect of achievement motivation on creativity by $55.2 \%$. (2) There is a direct effect of achievement motivation on working climate by $20.5 \%$. (3) There is a direct influence creativity on the working climate by $16 \%$. (4) 
There is a direct effect of achievement motivation on the productivity of trainers by $6.1 \%$. (5) There is a direct effect of creativity on productivity by $11.6 \%$. (6) There is a direct effect of working climate on the productivity of trainers at $12 \%$. (7) It is evident that the achievement motivation of trainers indirect effect on climate through productivity by $2.5 \%$. (8) It is evident that creativity trainers indirect effect on productivity through working climate by $1.9 \%$. (9) It is evident that achievement motivation and creativity together trainers directly influence the working climate at $63.3 \%$. (10) It is evident that achievement motivation, creativity and working climate jointly direct effect on the productivity of trainers at $72.6 \%$.

\section{Suggestion}

Based on the research and discussion that has been done, the authors put forward some suggestions as follows: (1) PPPPTK Technology is one institution that is below the Board of Education Human Resources Development and Quality Assurance of Education, Ministry of Education and Culture. (BPSDMPK \& PMP, KEMDIKBUD). Therefore let BPSDMPK \& PMP in formulating policies related to productivity of trainers concerned about achievement motivation, creativity and working climate. (2) Institute of Public Administration (LAN) as the institution responsible for the development of trainers have a very important role for increasing the productivity of trainers. Therefore let LAN make policies and decisions in the form of the policies that support productivity of trainers. Many trainers credit rate filing that is not recognized, it does not mean trainer concerned not do their job, but because these activities cannot be recognized as a task. Whereas in reality, these activities are activities that relate to the activities of educating, teaching and training. Additionally training for trainers that had been conducted by the LAN should be further increased in frequency as the number of trainers which quite a lot. This activity is very important for the trainers in order of increasing rank. (3) PPPPTK Technology should be recognize these characteristics in order to define measures for the improvement of achievement motivation, creativity and improved working climate because these factors are shown to affect the productivity of trainers. Some of the activities that can be done such as: Program hierarchy of educational qualifications, writing scientific papers, Prototype Creation and Development of media and learning aids. Additionally Management Board of PPPPTK Technology should involve trainers in the institution program development. (4) Trainers personally always working to improve achievement motivation and creativity to take advantage of each opportunity. Each task should be a welcome event to be creative. Trainers should also establish good communication between fellow trainers with management and other staff in the environment in order to maintain PPPPTK Technology have good working climate, because the working climate is also an impact on productivity .

\section{References}

[1] Head of the Institute of Public Administration Regulation No. 3 of 2010 on Technical Guidelines for Functional Trainers and credit figures.

[2] Regulation of the Minister of State for Administrative Reform No. 14 of 2009 on the Functional Trainers and credit figures.

[3] Ali Yassin et al. , 2012. Employees Working Conditions and Productivity in Manufacturing Companies in Sub- Saharan African . International Journal of Educational Research Vol 2, No.2, October 2013.

[4] Robbins, Stephen P. and DeCemzo, David., 2003. Fundamentals of Management Essential Concepts and Applications. Fourth Edition . New Jersey: Pearson Prentice Hall.

[5] Anoraga, Panji. , 2005, Work Psychology . Jakarta : Rineka Reserved.

[6] McBrien, J.L., and R. S. Brandt, 1997, The language of learning: A guide to education terms. Alexandria, VA

[7] Litwin, G.H., \& Stringer, R.A. Jr, 1968, Motivation and organizational climate, Boston: Harvard University Press.

[8] Alderfer., Clayton., 2007. ERG Theory of Motivation, p. 1. ERG Theory of Motivation http://www.Envision Software clayton p.alderfer.mht.

[9] Mc Clelland, 1953, The Achievement Motive, New York:Appleton-Century-Crofts, Inc.

[10] Gallagher, S. A, 1985, A comparison of the concept of overexcitabilities with measures of creativity and school achievement in sixth grade students. Roeper Review.

[11] Rani and Ms. Geeta Dalal , Suman., 2013. Relationship of Creativity and Achievement Motivation of Senior Secondary Students . Internatioanal Journal Of Research In Education Vol 2, July 2013. 